\title{
The NHS Act of 1951; Is it time to re-act?
}

Eye (2013) 27, 685-687; doi:10.1038/eye.2013.65

\section{NHS Bill of 1946}

The National Health Service (NHS) Bill of 30 April 1946 was welcomed by a weary society that had become accustomed to austerity following the efforts of World War II. The concept of free health care, including spectacles and dental treatment, was seen as a luxury, and there was a concerted effort by the rich and poor alike to co-operate to help make the NHS a success. It was the Minister's intention to provide all ophthalmic services under the NHS, and this was to be carried out only in hospitals within eye departments and clinics, which were to be run by specialist medical ophthalmologists, with ophthalmic opticians playing their 'proper professional part'. ${ }^{1}$

The Minutes from the first Annual General Meeting of the Faculty of Ophthalmologists on 1 June 1946 (Figure 1) revealed a mixed reaction to the NHS Bill. ${ }^{2}$ The Faculty in general welcomed the idea of opticians working under the supervision of ophthalmologists in the hospital setting and laid down three principles upon which the National Eye Service should be based:

(a) the ultimate responsibility of the care of the eyes must rest with an ophthalmologist of full specialist status;

(b) that the Government accept the principle that qualified sight-testing opticians have a proper and full professional part to play, in association with ophthalmologists, in the work of these clinics;

(c) that no one can receive ophthalmic attention from the specialist service unless he comes in through the recommendation of the general practitioner.

The NHS was subsequently born on 5 July 1948 due largely to the vision and determination of Aneurin (Nye) Bevan, the Minister of Health at the time.
G Ratnarajan ${ }^{1,2}$, R Wormald W $^{3,4}$ and N Astbury ${ }^{5,6}$

The availability of free sight tests and spectacles for the first time resulted in eager uptake of this service by the public, particularly among older persons who often required two pairs of glasses. This generated considerable expense, £25.9 million in 1949 and £24.7 million in 1950

\section{NHS Act of 1951}

The Chancellor of the Exchequer at the time, Hugh Gaitskell, addressed the increasing costs of the NHS in the NHS Act of 1951, which stated:

New Arrangements for the Supply of Glasses: As from 21st May 1951, a person of 16 years of age and over, and a child in certain circumstances, will be required to pay towards the cost of glasses -

(i) a sum of $£ 1$ per pair (or 10 s if one lens only is supplied) and

(ii) the whole cost of the National Health Service frames he selects.

This had an immediate effect, with the costs reducing to $£ 11.1$ million in 1952 , of which only approximately 6 million was from public funding. ${ }^{3}$ The expense of attempting to fully integrate optometric services into the hospital ultimately led to its dissolution in the 1951 Act, a similar fate to that of dental services. This is why, ever since, eyes and teeth have been inextricably combined in NHS administration. Nye Bevan resigned after the 1951 NHS Act was passed.

\section{Eye care delivery post 1951}

The provision of eye-care services is unique among medical specialties in that both a specialised medical and surgical service, in addition to a hugely widespread provision for sight testing, is required. Under the original NHS Act, both ophthalmologists and ophthalmic opticians carried out sight testing, with the former holding overall responsibility.
${ }^{1}$ Vision and Eye Research Unit, Postgraduate Medical Institute, Anglia Ruskin University, Cambridge, UK

${ }^{2} \mathrm{UCL}$ Institute of Ophthalmology, London, UK

${ }^{3} \mathrm{NIHR}$ Biomedical Research Centre at Moorfields Eye Hospital NHS Foundation Trust and UCL Institute of Ophthalmology, London, UK

${ }^{4}$ Cochrane Eyes and Vision Group, International Centre for Eye Health, London School of Hygiene and Tropical Medicine, London, UK

${ }^{5}$ Norfolk and Norwich University Hospital NHS Trust, Norwich, UK

${ }^{6}$ VISION 2020 (UK) Ltd

Correspondence:

G Ratnarajan, Vision and Eye Research Unit, Postgraduate Medical Institute, Anglia Ruskin University, East Road, Cambridge CB1 1PT, UK Tel: + 44 (0)7976 001102; Fax: + 44 (0)1753 430043 . E-mail: g.ratnarajan@ gmail.com 


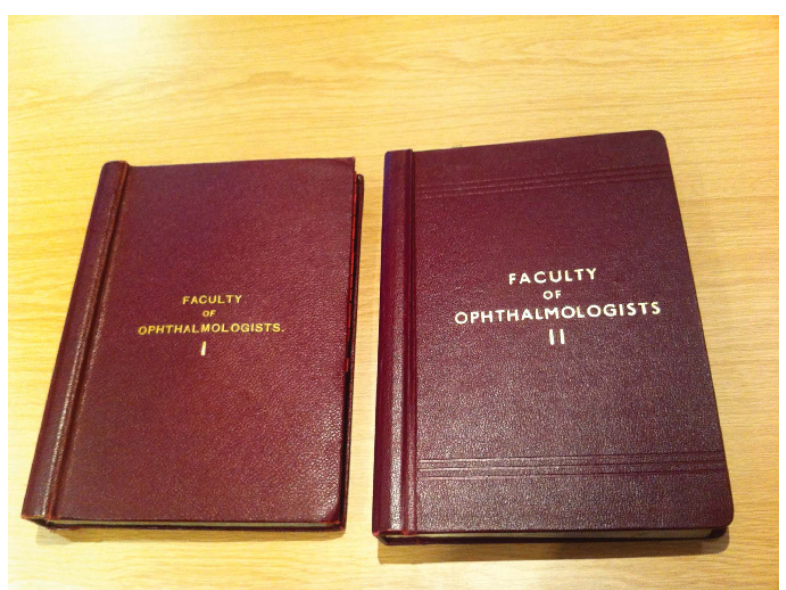

Figure 1 Photograph of Faculty of Ophthalmology Books kept at the Royal College of Ophthalmologists.

The NHS Act of 1951 meant that ophthalmic opticians would now carry out sight testing without direct medical oversight. This was a contradiction to the principles stipulated by the Faculty of Ophthalmologists after the National Health Service Bill, and raised significant concern among ophthalmologists.

Minutes from the Faculty of Ophthalmologists meeting of 29 February 1952 highlighted the divided opinion even within the Council, and after a great deal of discussion, Sir Stewart Duke-Elder proposed and Dr Scott seconded 'To concentrate on the improvement of ophthalmological standards in this country, leaving the screening of the public to a higher grade of ophthalmic optician'. ${ }^{4}$

Despite their approval, the Faculty expressed concerns whether ophthalmic opticians were fully competent to practise independent of medical supervision control and therefore suggested this practice be reserved for low-risk individuals aged between school-leaving age and the arbitrary age of 50 .

\section{Current Problem}

Nye Bevan's original concept to bring together these specialties under the NHS never materialized as it proved to be too costly. The NHS Act of 1951 created a fragmented eye service, which remains largely unchanged 60 years on, with community-based optometrists responsible for the correction of refractive error in the population as well as opportunistic screening of ocular disease. However, the commercially driven optometry model has resulted in a disparity of service provision where the socially deprived, who are known to present with more advanced disease or not at all, have the poorest access to optometry services. ${ }^{5,6}$ Our disintegrated eye health service needs to identify ocular pathology at an earlier stage, for which targeted surveillance of the high risk may be advantageous over opportunistic screening. ${ }^{7-9}$ This has already been successfully implemented in the NHS Diabetic Eye Screening Programme ${ }^{10}$ where the electronic transfer of patient information and imaging between community screening clinics and the Hospital Eye Service is now standard practice. Resource constraints have meant that similar models of care delivery have yet to be widely adopted in the other referral categories, namely cataract, glaucoma, and macula degeneration.

There is, more than ever, a need to bridge the longstanding gap between high street optometry and specialist hospital care. A national framework for enhanced services will enable optometrists and ophthalmologists to work collaboratively to improve the quality of referrals to the Hospital Eye Service, as well as safely review patients with stable disease who require life-long follow-up such as primary open-angle glaucoma.

\section{Summary}

Many of the problems associated with our fragmented eye-care system can be traced back to the formative years of the NHS. Nye Bevan's original concept of hospitalbased free eye-care, including the provision of spectacles and lenses, was widely welcomed. However, attempting to fully integrate optometric services into the hospital proved too costly and the NHS Act of 1951 placed optometry services outside the NHS, and also introduced a charge for spectacles and lenses. Since then, the gap from the commercially driven optometry sector and hospital eye services has widened. In particular, the socially deprived, who present with more advanced disease, are not being effectively identified by the current opportunistic case-finding model and calls for a reorganization of the delivery of eye health, which has remained largely unchanged since 1951. Targeted surveillance of the high-risk and enhanced service delivery systems at the primary and secondary care interface may help to bridge this gap between optometry and ophthalmology.

\section{Conflict of interest}

The authors declare no conflict of interest.

\section{Acknowledgements}

Mr Wormald received a proportion of his funding from the Department of Health's National Institute for Health Research (NIHR) Biomedical Research Centre for Ophthalmology at Moorfields Eye Hospital 
NHS Foundation Trust and the UCL Institute of Ophthalmology.

\section{References}

1 Giles G. The Ophthalmic Services Under the National Health Service Acts. Hammond, Hammond \& Company Ltd: London, 1953, pp 1946-1952.

2 Council of Ophthalmologists. Faculty of Ophthalmologists Book 1. Royal College of Ophthalmologists, 1946.

3 The Ophthalmic Service. Ophthalmic Service. Office of Health Economics: London, 1970.

4 Council of Ophthalmologists. Faculty of Ophthalmologists Book 2. Royal College of Ophthalmologists, 1952.

5 Day F, Buchan JC, Cassells-Brown A, Fear J, Dixon R, Wood F. A glaucoma equity profile: correlating disease distribution with service provision and uptake in a population in Northern England, UK. Eye 2010; 24(9): 1478-1485.

6 Fraser S, Bunce C, Wormald R, Brunner E. Deprivation and late presentation of glaucoma: case-control study. BMJ 2001; 322(7287): 639-643.

7 Glucoma Screening Platform Study Group, Burr JM, Campbell MK, Campbell SE, Franis JJ, Greene A et al. Developing the clinical components of a complex intervention for a glaucoma screening trial: a mixed methods study. BMC Med Res Methodol 2011; 11: 54.

8 Burr JM, Mowatt G, Hernandez R, Siddiqui MA, Cook J, Lourenco $\mathrm{T}$ et al. The clinical effectiveness and costeffectiveness of screening for open angle glaucoma: a systematic review and economic evaluation. Health Technol Assess (Winchester, England) 2007; 11(41): iii-iv, ix-x, 1-190.

9 Ratnarajan G, Wormald R. Peep into policy, politics, Parliament. Perspect Public Health 2013; 133(1): 7.

10 National Health Service Diabetic Eye Screening Programme. 2012. http://diabeticeye.screening.nhs.uk/. 